\title{
Comparing the Perceptions of Interprofessional Socialization Among Health Profession Students
}

\author{
Karen Aul \\ University of Florida, kaul@ufl.edu \\ Jody Long \\ Jacksonville State University, Alabama, jlong12@jsu.edu
}

Follow this and additional works at: https://nsuworks.nova.edu/ijahsp

Part of the Higher Education Commons, and the Other Medicine and Health Sciences Commons

\section{Recommended Citation}

Aul K, Long J. Comparing the Perceptions of Interprofessional Socialization Among Health Profession Students. The Internet Journal of Allied Health Sciences and Practice. 2020 Jan 01;18(3), Article 1.

This Manuscript is brought to you for free and open access by the College of Health Care Sciences at NSUWorks. It has been accepted for inclusion in Internet Journal of Allied Health Sciences and Practice by an authorized editor of NSUWorks. For more information, please contact nsuworks@nova.edu. 


\title{
Comparing the Perceptions of Interprofessional Socialization Among Health Profession Students
}

\begin{abstract}
Introduction: Based on a review of literature, there is a gap of knowledge on how students perceive the professional roles and responsibilities of other disciplines. The purpose of this study was to explore the perceptions of interprofessional socialization among health profession students. Subjects: Participants included 300 undergraduate and 114 graduate students from eight health disciplines: nursing, communication disorders, physical therapy, social work, radiological science, occupational therapy, clinical lab science, and nutritional science. Methods: Data were collected using the Interprofessional Socialization and Valuing Scale (ISVS-21). The participants rated 21 items about their beliefs, behaviors, and attitudes of interprofessional socialization on a Likert scale from 1-7, with 1 being not at all and 7 being to a very great extent. Data were analyzed using descriptive statistics and analysis of variance was conducted to compare the health disciplines for differences. Results: Descriptive analysis revealed that $95.2 \%$ of students perceived an awareness of interprofessional socialization as occurring from a fairly great extent to a great extent, with means of 5.12 or higher on the 1-7 scale. There were no significant differences between the health disciplines. Conclusion: Findings suggest that students have the readiness to understand each other's professional roles and responsibilities. Although there are no standardized educational strategies to facilitate student collaboration between disciplines, considerations for future interprofessional collaborative activities are indicated.
\end{abstract}

\section{Author Bio(s)}

Karen Aul, PhD, RN, CNE is a Clinical Assistant Professor in the College of Nursing at the University of Florida

Jody Long, EdD, LCSW is an Assistant Professor at Jacksonville State University in Alabama 


\title{
IUAHSP \\ The Internet Joumnal of Allied Health Sciences and Practice \\ Dedicated to allied health professional practice and education \\ Vol. 18 No. 3 ISSN 1540-580X
}

\section{Comparing the Perceptions of Interprofessional Socialization Among Health Professions Students}

\author{
Karen Aul 1 \\ Jody Long 2 \\ 1. University of Florida \\ 2. Arkansas State University \\ United States
}

\begin{abstract}
Introduction: Based on a review of literature, there is a gap of knowledge on how students perceive the professional roles and responsibilities of other disciplines. The purpose of this study was to explore the perceptions of interprofessional socialization among health profession students. Subjects: Participants included 300 undergraduate and 114 graduate students from eight health disciplines: nursing, communication disorders, physical therapy, social work, radiological science, occupational therapy, clinical lab science, and nutritional science. Methods: Data were collected using the Interprofessional Socialization and Valuing Scale (ISVS-21). The participants rated 21 items about their beliefs, behaviors, and attitudes of interprofessional socialization on a Likert scale from 1-7, with 1 being not at all and 7 being to a very great extent. Data were analyzed using descriptive statistics and analysis of variance was conducted to compare the health disciplines for differences. Results: Descriptive analysis revealed that $95.2 \%$ of students perceived an awareness of interprofessional socialization as occurring from a fairly great extent to a great extent, with means of 5.12 or higher on the 1-7 scale. There were no significant differences between the health disciplines. Conclusion: Findings suggest that students have the readiness to understand each other's professional roles and responsibilities. Although there are no standardized educational strategies to facilitate student collaboration between disciplines, considerations for future interprofessional collaborative activities are indicated.
\end{abstract}

Keywords: interprofessional socialization, health profession students, interprofessional education 


\section{INTRODUCTION}

Socialization, described as social interaction with others, is essential among health professionals who may have different beliefs, behaviors, and attitudes about what this means. Interprofessional education (IPE) serves as a channel for health professionals to learn effective collaboration. Interprofessional education has been defined as 2 or more professions learning together to develop the knowledge and skills for effective collaboration and team functioning. ${ }^{1-10}$ Barr and Watentor list a number of terms used for interprofessional education, including joint training, shared learning, and multiple-professional education. ${ }^{11}$ There is a three-goal health care approach to interprofessional education: improving the patient experience, improving the health of populations, and reducing the per capita cost of health care through patient-centered care. ${ }^{12}$ Interprofessional education can be defined as students engaging in teamwork, committing to efficient, high quality care in the patients' best interests, respecting teammates' skills and expertise, and willingness to work and communicate together. ${ }^{13}$

Increasing collaboration is supported by various organizations. For example, a plan for IPE and collaborative practice has been identified by The World Health Organization, and in 2010, the Institute for Medicine defined IPE as its goal and vision. ${ }^{1}$ In addition, effective teamwork is promoted by the World Health Association, The Agency for Health Care Research and Quality, and The American Association of Medical Colleges. As a result of the changing face of healthcare, a recent shift has occurred to maximize the quality of health care teams. Health care delivery shortcomings can be addressed by improving communication and relationships among health care professionals. Communication is critical to effective collaboration among health care professionals, patients, and family members. ${ }^{5}$ The essential requirement is for health care team members to form therapeutic alliances, which can be described as beneficial bonds or interactions. ${ }^{9}$ In order to facilitate these alliances, civility is an important element. ${ }^{1}$ Civility is defined as courteous, reasonable, and respectful behavior. ${ }^{2}$ Traditionally, it is seen as gracious, mannerly behaviors. Civility behaviors and attributes include effective communication, respectful interaction, positive relationships, and empathetic listening. Various organizations support the practice of civility in healthcare: The Institute of Medicine, The Joint Commission on Accreditation of Health Care Organizations, and American Association of Colleges of Nursing. ${ }^{16}$ Despite the importance of the inclusion of civility for effective communication and collaboration, incivility has been present within healthcare practice for decades. ${ }^{2}$ Woodworth concluded that incivility produces a work climate that places patients at risk for negative quality of care outcomes. ${ }^{5}$ In academia, the presence of incivility is significant for health care educators who build the foundation for effective communication and teamwork.

Interprofessional civility has been identified as a significant need in healthcare delivery. ${ }^{8}$ Civility is not only essential for current practitioners, but also for future health care practitioners. Health care educators are tasked to promote a positive culture of civility when educating students entering the health profession; nurses, physical therapists, social workers, occupational therapists, dieticians, and medical care assistants learn effective patient care with clinical rotations and direct patient care. ${ }^{5}$ The challenge for health care educators is to develop more inclusive than exclusive collaborative relationship among disciplines.

\section{Background}

Failures in communication at health care sites are common. ${ }^{7}$ An estimated seventy percent of preventable medical errors are a result of ineffective communication. ${ }^{3}$ The Joint Commission reported that 63 percent of all sentinel events are due to poor communication. ${ }^{14}$ Hence, effective healthcare members' communication and collaboration is critical for patient care. In the United States, The Joint Commission has identified communication and collaboration as a national healthcare practice goal. Collaboration can be elusive within current health care settings. ${ }^{15}$

Woodworth states the goal of graduate and undergraduate health professions is to develop student's knowledge of each other's roles and common dilemmas they may face, allow them to practice as team members, provide support for interprofessional communication and collaboration, and increase opportunities for interprofessional experiences in educational settings. ${ }^{2}$ The objective is an inclusive, integrated, curricular approach that promotes the students working as a team in patient care settings. ${ }^{6}$ There has been increasing pressure on universities to establish educational paths that enhance effective collaboration, teamwork, as well as quality and safety. This practice contravenes negative views and attitudes and improves quality of care. ${ }^{1}$

Educations' objective is to help students to create a positive team-based identity and to gain an appreciation for other disciplines. ${ }^{7}$ Part of this objective is to increase mindfulness and productive feedback while decreasing interpersonal tensions. ${ }^{6}$ There exists great necessity to build learning communities so that students can learn in a safe supportive environment. ${ }^{5}$ Regardless of discipline and degree pursuit, students require learning experiences to develop core teamwork competencies to prepare for professional practice. ${ }^{4}$

Along with national organizations, professional ethical standards and moral virtues support civility development. The qualities of civility include knowledge, skills, attitudes, and values that determine competencies indispensable for interprofessional 
communication. ${ }^{2}$ Burke, LeBlanc, and Henneman recommended that interprofessional education (IPE) should start early with graduate and undergraduate health care programs. ${ }^{9}$

\section{Purpose of the Study}

Although IPE has been identified and defined, a standardized effective educational format has not been established. Another area not researched is health profession students' perceptions of value for other professions. Only a limited number of studies exists which examines health care students' views of different disciplines. Based on the review of literature, there is a gap of knowledge on how students perceive the professional roles and responsibilities of other disciplines. This study will address the gap in researchbased knowledge of students' beliefs, attitudes, and behaviors. The purpose of this research study is to identify the perceptions of health profession students' views of different disciplines.

\section{METHODS}

A cross-sectional, descriptive study was performed. The perceptions of interprofessional socialization among health profession students were measured on a survey that included the participant's beliefs, attitudes, and behaviors. In order to increase the survey return rate, the Interprofessional Socialization and Valuing Scale (ISVS-21) was administered to all students in a face-to-face format. Since this was a preexisting survey, permission was obtained from the researchers through the Flintbox repository, a registered trademark of Wellspring Worldwide, LLC. This survey was developed from a psychometrically validated tool that was modified into a shorter version. ${ }^{18}$ The 21 -item IVIS produced strong internal consistency and had a Cronbach alpha of $0.988 .{ }^{19}$ The item format is 21 items that are scored via a 7-point Likert-type scale: 7 "To a very great extent," 1 = "Not at all" or N/A (not applicable). The independent variables were the demographic information of college major, traditional or nontraditional student, undergraduate or graduate student, gender, and ethnic/racial background.

\section{Selection of Participants}

The study sample consisted of a convenience sample of 414 undergraduate and graduate health profession students at one college of health professions. Eight disciplines were represented, the largest of which were 149 undergraduate nursing students, followed by 76 undergraduate communication disorder students, 52 graduate physical therapy students, 43 undergraduate social work students 35 undergraduate radiologic science students, 28 graduate occupational therapy students, 16 undergraduate clinical lab science students, and 15 undergraduate nutritional science students.

\section{Sampling Procedure}

After receiving approval from the Institutional Review Board, the researchers contacted faculty from eight health disciplines within the college of health professions: nursing, clinical lab science, occupational therapy, physical therapy, nutritional science, radiological science, social work, and communication disorders. The researchers arranged a mutually agreed upon day and time with the faculty member from each specific discipline to attend the start of their class to administer the survey face-to-face. There were no IPE events in any of the courses preceding the survey. Prior to distributing the surveys, the researchers introduced themselves and provided informed consent to the survey respondents. The IVIS-21 survey was then distributed to each willing participant. To ensure anonymity, the study participants were instructed not to write their names on the surveys and no personal identifiers were collected. A set of identical scripted directions was read to each group of health profession students to increase the consistency of data collection by different researchers. To collect data from the various classes taught by multiple faculty members, the researchers administered the survey over a two-month period. The researchers surveyed the students who were available on campus. However, there were several groups of students who were unable to be surveyed due to being off campus for clinical educational experiences.

\section{RESULTS}

\section{Participant Characteristics}

Data on the demographic information of college major, traditional or nontraditional student, undergraduate or graduate student, gender, and the ethnic/racial background was obtained from the first page of the survey. The sample of 414 health profession students represented $71.3 \%$ of traditional students and $28.7 \%$ of nontraditional students. The traditional student was defined by the researchers as a college student who was younger than 24 years of age, and a nontraditional student was a college student who was 24 years of age or older. There were $72.5 \%$ of undergraduate students and $27.5 \%$ of graduate students who completed the survey. Of the total participants, $81.9 \%$ students were female, and $18.1 \%$ students were male. The ethnic or racial background of the students was Caucasian (89.1\%), followed by African-American (5.3\%), Hispanic (2.2\%), and Asian (1.7\%); less than 1.7\% of the backgrounds of students were disclosed as Native American, Pacific Island, Caucasian-Asian, Caucasian, Pacific Islander, and other. Therefore, for the study sample, most of the participants were traditional, undergraduate female Caucasian students (Table 1). 
Table 1. Characteristics of Sample

\begin{tabular}{|l|l|l|l|}
\hline Characteristics & Category & $\begin{array}{l}\text { Number } \\
(\mathrm{n}=414)\end{array}$ & $\begin{array}{l}\text { Percentage } \\
(\%)\end{array}$ \\
\hline Type of Student & Traditional & 295 & 71.3 \\
\hline & Nontraditional & 119 & 28.7 \\
\hline Level of Student & Undergraduate & 300 & 72.5 \\
\hline & Graduate & 114 & 27.5 \\
\hline Gender & Male & 75 & 18.1 \\
\hline & Female & 339 & 81.9 \\
\hline Ethnic or Racial Background & Caucasian & 369 & 89.1 \\
\hline & African American & 22 & 5.3 \\
\hline & Hispanic & 9 & 2.2 \\
\hline & Asian & 7 & 1.7 \\
\hline & Other & 7 & 1.7 \\
\hline Health Profession & Nursing & 149 & 36 \\
\hline & Communication Disorder & 76 & 18.4 \\
\hline & Physical Therapy & 52 & 12.6 \\
\hline & Social Work & 43 & 10.4 \\
\hline & Radiologic Science & 35 & 8.5 \\
\hline & Occupational Therapy & 28 & 6.8 \\
\hline & Clinical Lab Science & 16 & 3.9 \\
\hline & Nutritional Science & 15 & 3.6 \\
\hline
\end{tabular}

\section{Data Analysis}

The quantitative responses for 21 items were analyzed from the IVIS-21 survey using SPSS software. The descriptive analyses were carried out using mean values and standard deviation. The mean for each question was determined according to how the participants rated their beliefs, attitudes, and behaviors of interprofessional socialization according to the Likert scale on the IVIS21 survey: $N / A=0$, not at all $=1$, to a very small extent $=2$, to a small extent $=3$, to a moderate extent $=4$, to a fairly great extent $=5$, to a great extent $=6$, and to a very great extent $=7$. The data analysis revealed that $95.2 \%$ of students perceived twenty out of twentyone items on the survey as occurring from a fairly great extent to a great extent, with $M=5.12$ or higher on the 1-7 Likert scale. The survey item with the highest mean ( $M=5.96)$ was "I have gained a better appreciation of the importance of a team approach." The lowest mean ( $M=4.8)$ was for the item of "I feel comfortable being the leader in a team situation." Table 2

displays the means for the survey items.

Table 2. Interprofessional Socialization and Valuing Scale Survey Results $(n=414)$

\begin{tabular}{|l|c|c|}
\hline Survey Item & Mean & $\begin{array}{c}\text { Standard } \\
\text { Deviation }\end{array}$ \\
\hline 1) Aware of preconceived ideas when entering team discussions & 5.12 & 1.17 \\
\hline 2) Better appreciation for using common language in team & 5.68 & 1.17 \\
\hline 3) Enhanced awareness of role on team & 5.57 & 1.15 \\
\hline 4) Able to share and exchange ideas in team discussion & 5.52 & 1.29 \\
\hline 5) Enhanced perception of self-engaging in interprofessional practice & 5.29 & 1.25 \\
\hline 6) Comfortable being leader in team situation & 4.80 & 1.46 \\
\hline 7) Comfortable speaking out within team & 5.35 & 1.39 \\
\hline 8) Comfortable describing professional role to team member & 5.58 & 1.17 \\
\hline 9) Better appreciation in sharing research across disciplines & 5.48 & 1.32 \\
\hline 10) Able to negotiate more openly with others in a team & 5.31 & 1.20 \\
\hline 11) Enhance awareness of roles of other team members & 5.44 & 1.23 \\
\hline 12) Comfortable engaging in shared decision-making with clients & 5.54 & 1.30 \\
\hline 13) Comfortable in accepting responsibility delegated within team & 5.91 & 0.99 \\
\hline 14) Better understanding of client decision-making around care & 5.82 & 1.19 \\
\hline 15) Comfortable clarifying misconceptions about role of profession & 5.41 & 1.15 \\
\hline
\end{tabular}




\begin{tabular}{|l|l|l|}
\hline 16) Better understanding of a team approach & 5.96 & 1.08 \\
\hline 17) Able to act as a fully collaborative member of team & 5.79 & 1.14 \\
\hline 18) Comfortable initiating discussions about shared client care & 5.47 & 1.26 \\
\hline 19) Comfortable sharing client decision-making with team & 5.65 & 1.11 \\
\hline 20) Gained more realistic expectations of other team members & 5.57 & 1.21 \\
\hline 21) Gained appreciation for benefits in interprofessional team work & 5.95 & 1.17 \\
\hline
\end{tabular}

The statistical method of analysis of variance (ANOVA) was used to test for mean differences among the groups of health disciplines. The ANOVA is the test for differences in the means in three or more groups. ${ }^{20}$ There were no significant differences found between the means from the groups of eight health disciplines: nursing, clinical lab science, occupational therapy, physical therapy, nutritional science, radiological science, social work, and communication disorders.

\section{DISCUSSION}

\section{Constructs of Perceptions}

This study aimed to explore the perceptions of health profession students' views of interprofessional socialization and values. The data collected on interprofessional socialization and values from the IVIS-21 scale was interpreted to look for differences in the students' perceptions of functioning within a collaborative care team. Our findings show that $95.2 \%$ of students perceived an awareness of interprofessional socialization as occurring from a fairly great extent to a great extent. This indicates that based on their participation in interprofessional education activities and/or clinical practice, students have a high perception of three main constructs: beliefs, attitudes, and behaviors. The first construct reinforces that they have positive beliefs about adopting a team member identity, understanding collaborative roles and responsibilities, and acknowledging the importance of a collaborative team approach. The second construct reveals that health profession students have attitudes of awareness of preconceived ideas and value the collaborative team approach. Finally, the results also support the behaviors of collaboration; which include articulating own role, clarifying misconceptions about roles, and confidence in displaying collaborative behaviors. Most of the participants bolstered certain beliefs, attitudes and felt they could demonstrate certain collaborative behaviors. These findings are relevant because they suggest that students have a readiness to understand each other's professional roles and responsibilities.

\section{Challenge for Educators}

Although most students demonstrate a readiness to learn the roles and responsibilities of other disciplines, the challenge for health care educators is to develop student's knowledge of each other's roles. ${ }^{2}$ The students may have the beliefs, attitudes, and behaviors, but are lacking the facilitation to learn the roles of other health disciplines. It is the educator who encounters the task of adding more inclusive collaborative relationships among disciplines. According to the NLN, "Educators must see themselves, not as profession-centric practitioners, but as interprofessional faculty charged with inspiring students to embrace and champion an interprofessional team-based health-care system."10 Woodworth found that it is important for the educator to increase these opportunities for interprofessional experiences in educational settings. ${ }^{2}$

Buhler suggests that students work as a team through an integrative approach. ${ }^{6}$ By working as a team as students, this can assist them to effectively collaborate as part of the multidisciplinary team of health care professionals once they graduate. As part of the team, the team members can do its collective best for the patient. ${ }^{21}$ An integrative approach for interprofessional education during students' education at such a formative stage of their careers is essential to enhance these team relationships. Considerations for interprofessional collaborative activities are clearly indicated; the challenge is how to effectively integrate those activities into educational programs.

\section{Limitations}

There were limitations in the study. One limitation was lack of diversity in sampling. The participants were predominantly traditional, undergraduate, female and Caucasian. The participants were all health profession students as the sampling did not include the perceptions of practitioners. It would make for an interesting study to compare the perceptions about interprofessional socialization between the health profession students and the practitioners. Another limitation in the study was potential bias since most of the references were from nursing focused publications. However, to decrease researcher bias, the primary investigator included an additional researcher who represented a health profession other than nursing and various types of health profession students were included as selected participants. 


\section{CONCLUSION}

The results from this study further support the need for integrating interprofessional education into the curricula of students to learn about the roles of other health professions. The need for health profession students to understand other disciplines is essential to work across disciplinary boundaries. There is an increasing reliance on inclusive collaboration and open communication to provide safe quality patient care. The future goal is to incorporate strategies into academia to achieve the team-based cross-disciplinary collaboration in health care.

\section{References}

1. Feather, R. A., Carr, D. E., Reising, D. L., \& Garletts, D. M. Team-based learning for nursing and medical students. Nurse Educator. 2016; 41(4):E1-E5.

2. Woodworth, J. A. Promotion of nursing student civility in nursing education: A concept analysis. Nursing Forum. 2016; 51(3):196-203.

3. Arentsen, A., Welsh, D., Jones, M., Weber, D., Taylor, S., Kuperstein, J., Rayens, M. K., \& Salt, E. Student perception of improvement in communication and value in 2 interprofessional education delivery formats. Nurse Educator. 2016; 41(2):9092.

4. Rossler, K. L., Buelow, J. R., Thompson, A. W., \& Knofczynski, G. Effective learning of interprofessional teamwork. Nurse Educator. 2016; 00(0):1-5.

5. De Gagne, J. C., Choi, M., Ledbetter, L., Kang, H. S., \& Clark, C. M. An integrative review of cybercivility in health professions education. Nurse Educator. 2016; 41(5):239-245.

6. Buhler, A. V., Coplen, A. E., Davis, S., \& Nijjar, B. Comparison of communications styles among students in allied health professions programs: How do our students communicate with other healthcare providers? JRIPE. 2016; (2):1-14.

7. McCrorie, P., Roberts, P.A., \& Sainsbury, D. Perceptions of nursing and physical therapy students toward peer-led interprofessional education in manual handling. Nurse Educator. 2016; 00(0):1-6.

8. Horsley, T. L., Reed, T., Muccino, K., Quinones, D., Siddall, V, J., \& McCarthy, J. Developing a foundation for interprofessional education within nursing and medical curricula. Nurse Educator. 2016; 41(5):234-238.

9. Burke, M.E., LeBlanc, R.G., \& Henneman, E.A. ABCDs of professional introduction:Teaching nursing students the most fundamental of all communication skills. Nurse Educator. 2016; 41(3):115-116.

10. National League for Nursing (NLN). Interprofessional Collaboration in Education and Practice: A Living Document from the National League for Nursing. 2015. http://www.nln.org. Accessed Jan. 19, 2018.

11. Barr, H. \& Watenton, S. Summary of CAIPE survey: Interprofessional education in health and social care in the United Kingdom. Journal of Interprofessional Care.1996; 10(5): 297-303.

12. Kirch, D.G. \& Ast, C. Interprofessionalism: Educating to meet patient needs. Anatomical Sciences Education. 2014; 8:296298.

13. Judge, M.P., Polifroni, E.C., \& Zhu, S. Influence of student attributes on readiness for interprofessional learning across multiple healthcare disciplines: Identifying factors to inform educational development. IJNSS. 2015; 2(3):248252.

14. The Joint Commission. Behaviors that undermine a culture of safety. Sentinel Event Alert. 2008;40.

15. Maranzan, K.A. Interprofessional education in mental health: An opportunity to reduce mental illness stigma. Journal of Interprofessional Care. 2017; 30(3):370-377.

16. Ulrich, B. Sentinel event alert: The essential role of leadership in developing a safety culture. Nephrology Nursing Journal. 2017; 44(2):109-184.

17. Coster, S., Norman, I., Murrells, T., Kitchen, S., Meercheau, E., Sooboodoo, E., \& d'Avray, L. Interprofessional attitudes amongst undergraduate students in the healthcare professionals: A longitudinal questionnaire survey. Journal of Nursing Studies. 2008; 45(11): 1667-1681.

18. King, G., Shaw, L., Orchard, C., \& Miller, S. The Interprofessional Socialization and Valuing Scale: A tool for evaluating the shift toward collaborative care approaches in health care settings. Work. 2010; 35:77-85.

19. King, G., Orchard, C., Khalili, H. \& Avery, L. Refinement of the Interprofessional Socialization and Valuing Scale (IVIS-21) and development of 9-item equivalent versions. JCEHP. 2016; 36(3):171-177.

20. Rebar, C. R., Gersch, C. J., Macnee, C. L., \& McCabe, S. Understanding Nursing Research: Using Research in EvidenceBased Practice, 3rd edition. 2011. Philadelphia, PA: Wolters Kluwer Health/Lippincott Williams \& Wilkins.

21. Mayo, A. T. \& Woolley, A.W.Teamwork in health care: Maximizing collective intelligence via inclusive collaboration and open communication. AMA Journal of Ethics. 2016; 18(9):933-940.

22. Socialization (n.d.). Merriam-Webster Online. http://www.merriam-webster.com/dictionary/citation. 